\title{
Epidemiology of Enterobiasis in Palestine
}

\author{
RESEARCH
}

\section{Omar Hamarsheh}

Department of Life Sciences, College of Science \& Technology, Al-Quds University, P.O. Box 51000, Jerusalem, Palestine

\begin{abstract}
A B S T R A C T
Enteropiasis is a parasitic disease caused by the pinworm; Enterobius vermicularis. In this report, the prevalence of Enterobius vermicularis infection in the West Bank and Gaza strip was investigated based on Palestinian Ministry of Health reports from 2008 to 2018. A total of 29,390 cases was reported, 29,061 (98.9\%) in the West Bank, and 329 cases (1.1\%) in Gaza Strip. The results of the present study show that E. vermicularis infection is highly prevalent among people living in the West Bank and to lesser extend in Gaza Strip. There is a need for joint and concentrated efforts from the Palestinian government and public health services to control this infection. Personal hygiene, education and living conditions and overcrowding are risk factors associated with the spread of infection.
\end{abstract}

Keywords: Enterobius vermicularis, Palestine, infectious diseases, West Bank, Gaza

\section{Introduction}

Parasitic infections are among the common contagious diseases of the Palestinian community (Hamarsheh and Amro 2020), previous reports documented the widespread of certain parasitic infections like Leishmaniasis (Amro and Hamarsheh 2020), scabies (Hamarsheh 2020, Amro and Hamarsheh 2012), intestinal parasites (Astal 2004, Mezeid et al. 2014, Al-Hindi 2002, alAgha and Teodorescu 2000).

Enterobiasis is a cosmopolitan parasitosis caused by the pinworm Enterobius vermicularis (E. vermicularis). Direct contact between infected individuals with others are considered the main rout of transmission (Sato et al. 2008, Al-

\footnotetext{
* Correspondance:

Department of Biological Sciences, Faculty of Science and Technology, P. O. Box 51000, East Jerusalem, Palestine Tel: 00972-599197097 / Fax: 00972-22796960

Email: ohamarsheh@staff.alquds.edu
}

(C) copy rights 2021: All materials in this article are protected, permission requests should be addressed Al-Quds University.

www.alquds.edu
Hindi 2002, Stoyanova et al. 2020). Many studies have been conducted to explore the risk factors associated with enterobiasis disease. The main risk factors are associated with indoor living conditions, including personal sanitary and close contact with other people, as pinworms spread mainly indoors directly from one human to another (Abu Mourad 2004, Acosta, et al. 2002, Kim et al. 2010, Song et al. 2003).

Crowded communities like refugee camps and overcrowded regions are optimal for the transmission and spread of enterobiasis. Kindergartens, nurseries and primary schools are places with high transmission risks (Hussein 2011, Remm 2006). The disease is not fatal and may remain asymptomatic or cause perianal pruritus, insomnia, restlessness, irritability, and rarely, impetigo of scratched skin, vulvovaginitis, or enuresis. Although effective medications have been available for decades, control of enterobiasis has been difficult because of 
reinfection, incomplete cure of infected people, and its ready transmissibility. The symptoms of enterobiasis are not fatal, and it can be readily transmitted via direct contact between infected and uninfected persons. Although the majority of infections are asymptomatic, they can induce bothersome symptoms in some cases, including an itching sensation and irritation in the perianal area, along with mental distraction. The disease is asymptomatic in adults, however, in children, particularly those with high worm burdens, restlessness, irritability, and distraction may occur, and these may influence child growth (Karamitros et al. 2017, Carrillo-Quintero et al. 2016, Fedotova 1999). E. vermicularis infection is prevalent in many countries of the world, including developed countries. E. vermicularis infection is diagnosed among school children in Palestine and according to the Ministry of Health annual reports, the average prevalence of the infection reaches very high levels (Hamarsheh and Amro 2020). There are many studies to explore the epidemiology of parasitic diseases in Palestine (Hamarsheh and Amro 2020, Hindi 2014, Kanoa and Al-Hindi 2009, Astal 2004, Abu Mourad 2004). Currently, little information is available regarding the prevalence and the risk factors of enterobiasis. Therefore, this report aims to investigate status and prevalence of enteropiasis disease in the West Bank and Gaza strip.

\section{Methods}

Study areas

The study were carried out in the West Bank and Gaza Strip. These geographical areas are unconnected and almost separated. The West Bank consists of the following districts: Hebron, South Hebron, Bethlehem, Jerusalem, Ramallah, Jericho, Nablus, Jenin, Tubas, Tulkarem, Qalqilya, and Salfit. The Gaza Strip has the following districts: North Gaza, Gaza City, Deir Al Balah, Khan Younis, and Rafah (see Figure 1). The total Palestinian population in 2017 was 4.95 million (three millions in the West Bank and 1.95 million in Gaza Strip). About $66.2 \%$ of the Palestinian population residing in the Gaza Strip and most of the people there live in overcrowded areas, on the other hand $26.6 \%$ residing in the West Bank with more space and open areas, even though there are number of refugee camps in the West Bank.

\section{Data collection and analysis}

Since enteropiasis disease is considered one of the reportable parasitic diseases, the Palestinian Ministry of Health annual statistical reports were screened for the years 2008 until 2018 (the latest published report). For data analysis detailed epidemiological information about the diseases, and the number of patients per year in each Palestinian district was determined and arranged in spread sheet.

\section{Results}

Enteropiasis Disease is existed in most Palestinian districts of the West Bank and in all districts in Gaza Strip (Figure 1).

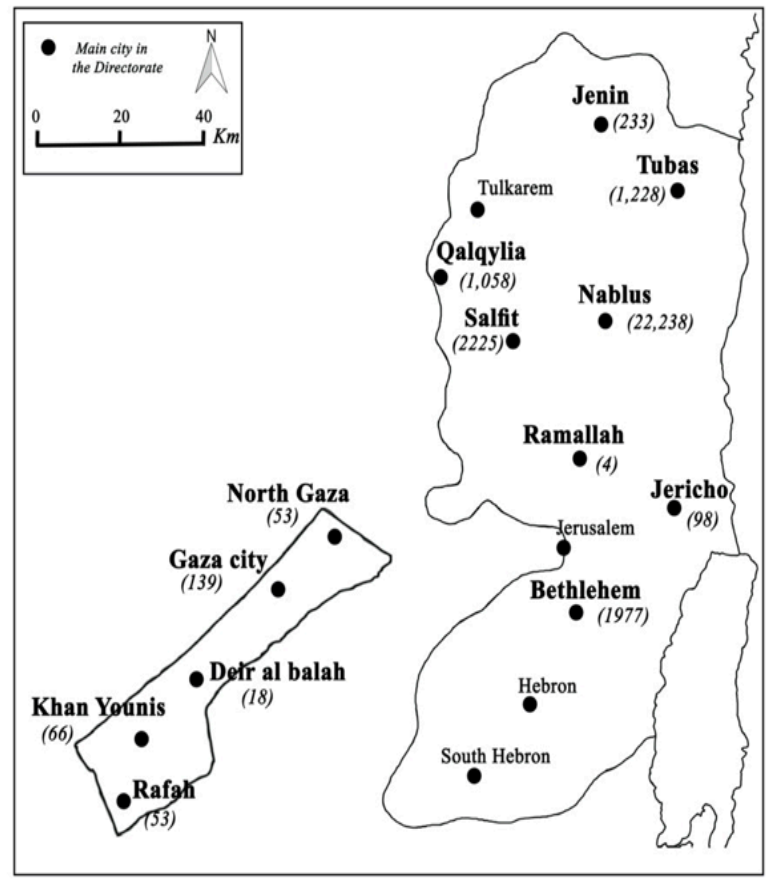

Figure 1: Map of the West Bank and Gaza Strip, Palestine shows the distribution of enteropiasis disease in the country from 2008-2018

The total number of cases in Palestine from 2008 to 2018 was 29,390 cases, among them; 29,061 (98.9\%) in the West Bank, while the others 
329 cases (1.1\%) in Gaza Strip. Nablus district was found to have the highest number of cases (75.7\%) followed by Salfit (7.6\%), Bethlehem (6.7\%), Tubas (4.2\%), and Qalqylieh (3.6\%). The other districts; Hebron, South Hebron, and Jerusalem were totally free of the disease or have very low numbers; Jenin (0.8\%), Jericho (0.3\%), and Ramallah (0.01\%). The distribution of cases per year and district are shown in Table 1. The yearly trend of the disease, as shown in Figure 2 is relatively steady with slight fluctuations, the highest peak (13740 cases), and the lowest peak was in 2011 where only 624 cases. There is a peak in 2010 and 2013 with 1748 and 2595 cases reported respectively. From 2016 and ahead there is slight change on the number of reported cases every year.

Table 1: Total number of Enterobiasis patients from 2008-2018 in each directorate.

\begin{tabular}{|c|c|c|c|c|c|c|c|c|c|c|c|c|}
\hline District & 2008 & 2009 & 2010 & 2011 & 2012 & 2013 & 2014 & 2015 & 2016 & 2017 & 2018 & Total \\
\hline N.Gaza & 1 & 5 & 2 & 3 & 7 & 19 & 8 & 2 & & 6 & & 53 \\
\hline Gaza City & 3 & 5 & 33 & 49 & 8 & 11 & 2 & 15 & 5 & 7 & 1 & 139 \\
\hline Deir Al-Balah & 1 & 1 & 1 & 2 & 5 & 1 & & 4 & & & 3 & 18 \\
\hline Khan Younis & & & 25 & 4 & 3 & 5 & 26 & & & & 3 & 66 \\
\hline Rafah & 3 & 11 & 6 & 7 & 8 & 3 & 8 & 4 & & 2 & 1 & 53 \\
\hline Sum (Gaza Strip) & 8 & 22 & 67 & 65 & 31 & 39 & 44 & 25 & 5 & 15 & 8 & 329 \\
\hline Hebron & & & & & & & & & & & & 0 \\
\hline S.Hebron & & & & & & & & & & & & 0 \\
\hline Bethlehem & 62 & 198 & 113 & 91 & 252 & 340 & 253 & 267 & 170 & 97 & 134 & 1977 \\
\hline Jerusalem & & & & & & & & & & & & 0 \\
\hline Ramallah & & & & & & & & & & & 4 & 4 \\
\hline Jericho & 2 & 20 & 1 & 2 & 21 & 7 & 11 & 25 & 4 & 1 & 4 & 98 \\
\hline Nablus & 13424 & 1342 & 1371 & 416 & 1210 & 1430 & 1199 & 503 & 469 & 414 & 460 & 22238 \\
\hline Jenin & & & & & & & & 213 & 9 & 9 & 2 & 233 \\
\hline Tulkarem & & & & & & & & & & & & 0 \\
\hline Qalqylieh & 25 & 135 & 36 & 10 & 19 & 98 & 109 & 113 & 114 & 167 & 232 & 1058 \\
\hline Salfit & 219 & 243 & 160 & 40 & & 358 & 315 & 224 & 206 & 211 & 249 & 2225 \\
\hline Tubas & & & & & 157 & 323 & 246 & 213 & 149 & 88 & 52 & 1228 \\
\hline Sum (West Bank) & 13732 & 1938 & 1681 & 559 & 1659 & 2556 & 2133 & 1558 & 1121 & 987 & 1137 & 29061 \\
\hline Total Palestine & 13740 & 1960 & 1748 & 624 & 1690 & 2595 & 2177 & 1583 & 1126 & 1002 & 1145 & 29390 \\
\hline
\end{tabular}

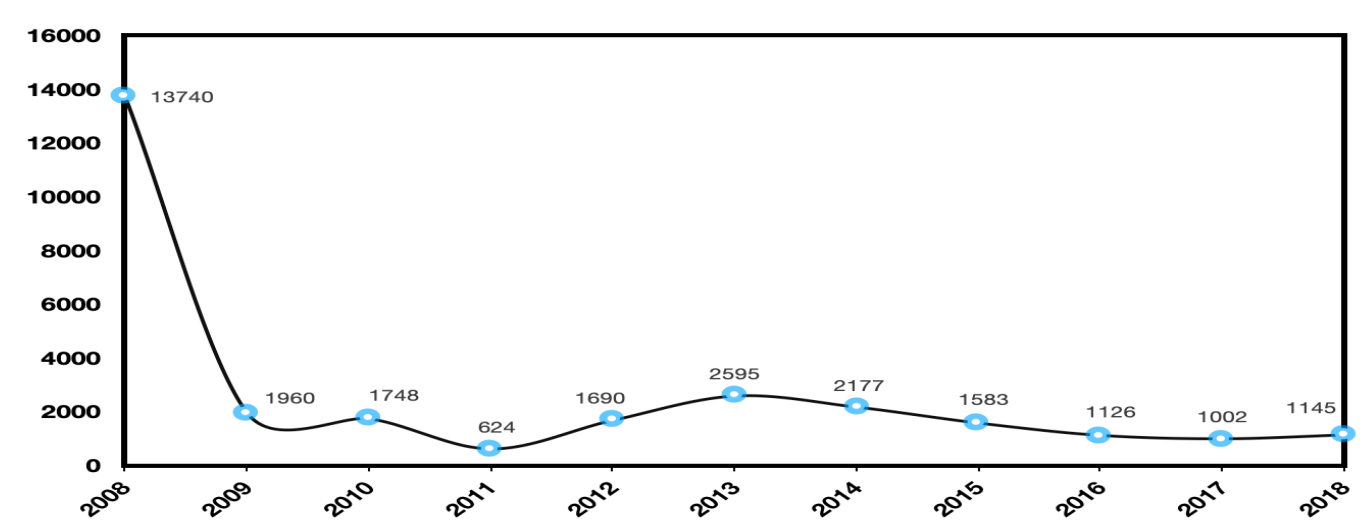

Figure 2:

The yearly trends

of enterobiasis

from 2008 to 2018

as total number

of cases per year. 


\section{Discussion}

The infection rate of entorobiasis was compared between directorates in the West Bank and Gaza Strip from 2008 to 2018. The disease was prevalent in the West Bank (98.9\%), the majority of cases are distributed in certain directorates; the disease is highly endemic in Nablus and this is not surprising since this directorate is considered highly populated and have many overcrowded refugee camps, other parasitic diseases were reported previously in this directorate (Hamarsheh and Amro 2020). Tulkarem, Hebron, Jerusalem and South Hebron directorates in the West Bank are totally free of the infection. Low numbers in Hebron district and Jerusalem is probably due to problems in the reporting system since most of Jerusalem area is under Israeli control and enteropiasis cases are counted as Israeli cases. On the other hand, very few cases reported in Ramallah directorate (4 cases in 2018 only), and in Jenin (233 cases ) from 2015 to 2018. Distribution of the infection in Gaza strip is considered very low compared with the distribution of the disease in the West Bank directorates (329 cases in Gaza Strip in 10 years). The unequal distribution of the eneteropiasis cases in the Palestinian directorates should be subjected for further research, overcrowdings seems not the only factor that support and maintain the infection in the country. Variations between inhabitants in socioeconomic levels, personal hygiene, nutrition, education, and living conditions are important factors that may have a role in the spread of the disease.

The high infectivity of E. vermicularis is due to multiple transmission modes (anus to mouth, food, dust, retrograde from anus to intestine) and prolonged egg viability (14 days). This is different from other helminths, it can reproduce in humans without passing through an intermediary soil phase. Thus, it can be transmitted from person to person. In rural or overcrowded areas enterobiasis transmission is facilitated by difficulties in maintaining good personal hygiene. These living conditions are available in Palestine. Although enterobiasis disease is not fatal, but considered to be a nuisance. The level of morbidity is significant, particularly in children. Therefore, this worm is one of the most frequently encountered and ubiquitous nematodes. Although enterobiasis can be readily cured by anthelmintic medications, the prevalence of this infection in Palestine has not significantly diminished yet. Personal hygiene is closely associated with E. vermicularis infection, inadequate personal hygiene can increase the risk of enterobiasis among primary school children. Other factors that significantly associated with enterobiasis include playing on the floor, nail biting, failure to wash hands before meals, inappropriate living conditions in marginalized or rural poor dwellings. Further research is crucial to identify environmental risk factors associated with enterobiasis especially in nurseries and kindergartens.

In conclusion, E. vermicularis infection was widely prevalent in some directorates in the West Bank. Therefore, raising awareness and systematic control and preventive programs for children at schools should be implemented in order to eradicate $E$. vermicularis infection.

\section{Acknowledgements}

This work was supported by a grant from Palestinian Ministry of Higher Education.

\section{Conflict of interest}

The author declare no conflict of interest in relation with this manuscript.

\section{References}

Abu Mourad, T. A. 2004. "Palestinian refugee conditions associated with intestinal parasites and diarrhoea: Nuseirat refugee camp as a case study." Public Health 118 (2):131-42. doi: 10.1016/j. puhe.2003.09.002.

Acosta, M., D. Cazorla, and M. Garvett.2002." "Enterobiasis among schoolchildren in a rural population from Estado Falcón, Venezuela, and its relation with socioeconomic level]." Invest Clin 43 (3):173-81.

al-Agha, R., and I. Teodorescu. 2000. "Intestinal parasites infestation and anemia in primary school children in Gaza Governorates--Palestine." Roum Arch Microbiol 
Immunol 59 (1-2):131-43.

Al-Hindi, A. I. 2002. "Prevalence of intestinal parasites among school children in Deir El-Balah Town in Gaza Strip, Palestine." Ann Saudi Med 22 (3-4):2735. doi: 10.5144/0256-4947.2002.273.

Amro, A, and O Hamarsheh. 2020. "Epidemiology of Leishmaniasis in Palestine." In Handbook of Healthcare in the Arab World, edited by I Laher, 1-17. Cham, Switzerland: Springer.

Amro, A., and O. Hamarsheh. 2012. "Epidemiology of scabies in the West Bank, Palestinian Territories (Occupied)." Int J Infect Dis 16 (2):e117-20. doi: 10.1016/j.ijid.2011.10.005.

Astal, Z. 2004. "Epidemiological survey of the prevalence of parasites among children in Khan Younis governorate, Palestine." Parasitol Res 94 (6):449-51. doi: 10.1007/s00436-004-1234-1.

Carrillo-Quintero, D., L. Del Otero Sanz, S. Hernández-Egido, and A. M. Martín Sánchez. 2016. "[Demographic and clinical features of diagnosed individuals of enterobiasis in the southern Gran Canaria: sampling assessment]." Rev Esp Quimioter 29 (6):302-307.

Fedotova, G. P. 1999. "[Enterobiasis in preschool institutions]." Med Parazitol (Mosk) (1):61-2.

Hamarsheh, O. 2020. "Epidemiology of Scabies in Palestine." In Handbook of Healthcare in the Arab World, edited by I Laher, 1-14. Cham, Switzerland: Springer.

Hamarsheh, O., and A. Amro. 2020. "Epidemiology of Parasitic Infections in the West Bank and Gaza Strip, Palestine." Am J Trop Med Hyg 102 (2):313317. doi: 10.4269/ajtmh.19-0545.

Hindi, A. 2014. "The awareness of health professionals in diagnostic techniques for intestinal parasites in gaza strip, palestine." Ann Med Health Sci Res 4 (1):80-4. doi: 10.4103/2141-9248.126621.

Hussein, A. S. 2011. "Prevalence of intestinal parasites among school children in northern districts of West Bank-Palestine." Trop Med Int Health 16 (2):240-4. doi: 10.1111/j.1365-3156.2010.02674.x.
Kanoa, B. J., and A. I. Al-Hindi. 2009. "Mother knowledge, attitudes, perception regarding intestinal parasites and diarrhoea in three regions of Gaza strip, Palestine." J Egypt Soc Parasitol 39 (3):82736.

Karamitros, G., N. Kitsos, and F. Athanasopoulos. 2017. "A case of enterobiasis presenting as posttraumatic-stress-disorder (PTSD): a curious case of the infection with predominant mental health symptoms, presenting for the first time in the settings of a refugee camp." Pan Afr Med J 27:111. doi: 10.11604/pamj.2017.27.111.12870.

Kim, D. H., H. M. Son, J. Y. Kim, M. K. Cho, M. K. Park, S. Y. Kang, B. Y. Kim, and H. S. Yu. 2010. "Parents' knowledge about enterobiasis might be one of the most important risk factors for enterobiasis in children." Korean J Parasitol 48 (2):121-6. doi: 10.3347/kjp.2010.48.2.121.

Mezeid, N., F. Shaldoum, A. I. Al-Hindi, F. S. Mohamed, and Z. E. Darwish. 2014. "Prevalence of intestinal parasites among the population of the Gaza Strip, Palestine." Ann Parasitol 60 (4):281-9.

Remm, M. 2006. "Distribution of enterobiasis among nursery school children in SE Estonia and of other helminthiases in Estonia." Parasitol Res 99 (6):729-36. doi: 10.1007/s00436-006-0220-1.

Sato, M., S. Sanguankiat, S. Pubampen, and T. Kusolsuk. 2008. "Enterobiasis: a neglected infection in adults." Southeast Asian J Trop Med Public Health 39 (2):213-6.

Song, H. J., C. H. Cho, J. S. Kim, M. H. Choi, and S. T. Hong. 2003. "Prevalence and risk factors for enterobiasis among preschool children in a metropolitan city in Korea." Parasitol Res 91 (1):46-50. doi: 10.1007/s00436-003-0836-3.

Stoyanova, K., S. Pavlov, T. Cvetkova, and T. Paunov. 2020. "Prevalence and Age Distribution of Enterobiasis in North-Eastern Bulgaria." Helminthologia 57 (2):100-108. doi: 10.2478/helm2020-0019. 